Research Article

\title{
Screening of Biological Effectiveness of Endophytic Fungi Associated with Plectranthus amboinicus: A focus on Aspergillus terreus
}

\author{
Tejaswini, H.K*, Jayashankar, M. and Mohammed Ali Saeed \\ Department of Studies and Research in Microbiology, Mangalore University, \\ Post Graduate Centre, Jnana Kaveri campus, Kodagu, Karnataka, India. \\ *Corresponding author's E-mail: tejaswinigowda1393@gmail.com
}

Received: 16-04-2021; Revised: 18-06-2021; Accepted: 25-06-2021; Published on: 15-07-2021.

\section{ABSTRACT}

Endophytic fungi produce a diverse range of bioactive molecules, which aids to produce a rich source of different types of medicines. The present study aims to evaluate the antimicrobial, antioxidant, and antidiabetic activity of fungal endophytes associated with edible leaves Plectranthus amboinicus (Indian borage). The results of preliminary screening of antibacterial activity showed inhibition against all tested pathogens similarly, crude ethyl acetate extract of all the isolates in the secondary screening of antidiabetic activity showed a good zone of inhibition with minimum inhibitory concentration (MIC) and minimum bactericidal concentration (MBC). The antioxidant activities were also determined by using the TPC, FRAP, and DPPH assay, which showed considerable variations concerning their positive control. The correlation among antioxidant assays indicated a strong correlation between TPC and DPPH. Also, the antidiabetic activity by alpha-amylase inhibition assay showed good inhibitory activity in different concentrations. Thus, the study suggested that endophytes from this edible plant could be potential source for the production of broad-spectrum antimicrobial, antioxidant, and antidiabetic compounds.

Keywords: Plectranthus amboinicus (Indian borage), Endophytic Fungi, Antibacterial, Antioxidant, Antidiabetic.

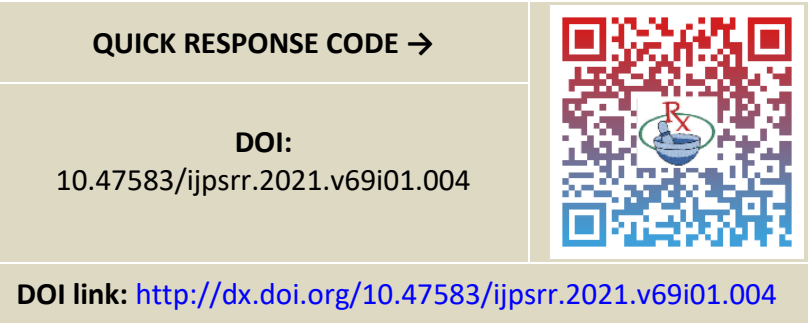

\section{INTRODUCTION}

$\mathrm{H}$ uman health is developing complicated diseases day by day due to current lifestyle and changes in their food habits, which leads to the search of new antibiotics for multiple drug-resistant microbes ${ }^{1,2,3}$. Urgent search for newer and more effective antibiotics that should be cheap and have a minimal environmental impact to deal with these disease problems is now underway. Hence, plant-associated endophytes that are relatively unexplored can be studied for the extraction of a substance containing secondary metabolites ${ }^{4}$. Endophytes have a mutual relationship inside healthy plant tissue and are found abundantly in some part or in the whole plant which spends their whole life or a period of life cycle, without causing any disease symptoms ${ }^{5}$. Endophytic fungi have been widely studied and discovered to produce a significant variety of natural products ${ }^{6,7}$. They often synthesize several novel metabolites such as alkaloids, terpenoids, steroids, quinones, isocoumarin derivatives, and flavonoids ${ }^{8}$ with various pharmaceutical applications such as herbicidal, anticancer, anti-diabetic, anti-microbial, and immunosuppressant ${ }^{9,10}$. Secondary metabolites produced by the endophytes are similar to those produced by the host, as a consequence of genetic exchange. Thus, it can be said that endophytic fungi have emerged as an alternative source for the production of novel drugs.

From ages, plants were used as traditional medicine due to their curative properties to treat various diseases. Studies has shown that the curative property of medicinal plant is not only because of chemicals present in the plant but also because of the endophytes that reside within the plants hence search for new bioactive strains of endophytic fungi played a very important role in the present scenario ${ }^{11,12}$. Plectranthus amboinicus, is a perennial herb know as Indian borage, it is widely used as medicinal plant commonly found in tropical countries ${ }^{13}$. Traditionally used to treat variety of medicinal applications such as fever, cough, skin infections, throat infection, constipation and digestive problems ${ }^{14,15}$. Early research data discloses that the plant possesses antimicrobial, antioxidant and phytochemical properties having 70 volatile and 30 non-volatile compounds with significant pharmacological properties $^{16,17}$. The leaves of this herb are also used for flavouring and in preparation of traditional food ${ }^{18}$ hence, the present study was carried out to isolate endophytic fungi from Plectranthus amboinicus and to investigate their biological properties such as antimicrobial, antioxidant and antidiabetic activities.

Globally, complicated diseases have been of concern such as Diabetes mellitus (DM), a metabolic disorder considered as a major health concern due to its prevalence that results in the deficiency in insulin secretion, insulin action, or both promoting disturbance of carbohydrate, fat, and protein metabolism by alpha-amylase ${ }^{19}$. These antioxidants also gaining importance in protecting the body against reactive 
oxygen species (ROS) toxicity either by removing or by converting those to less reactive molecules, and it is also produced in numerous biochemical reactions in the body and has been implicated as mediators of many diseases, including cancer, atherosclerosis and heart diseases ${ }^{20}$. In recent years, herbal medicine is used all over the world for health care management due to fewer side effects compared with synthetic medicine. In an effort the search for possible sources of novel therapeutic compounds, the present study was carried out to isolate endophytic fungi from Plectranthus amboinicus and to investigate their biological properties such as antimicrobial, antioxidant, and antidiabetic activities.

\section{MATERIALS AND METHODS}

\section{Sample Collection}

Fresh and symptomatic leaves of Plectranthus amboinicus (Indian borage) were collected from Chikka Aluvara, Kodagu District, Karnataka, India. Leaves were collected in sterile polythene bags and immediately washed with tap water and processed for isolation of endophytic fungi.

\section{Isolation of endophytic fungi}

Leaves were washed thoroughly in running tap water for $10 \mathrm{~min}$ to remove dust, debris, soil and minimize the microbial load from the sample surface. The surface sterilization process was carried out as per the procedure described by ${ }^{21}$ with minor modification. The leave samples were surface sterilized with $70 \%$ ethanol for $1 \mathrm{~min}, 4 \%$ sodium hypochlorite for $3 \mathrm{~min}$ followed by $70 \%$ ethanol for 30 seconds, and finally washed thoroughly in sterile distilled water to remove the traces of alcohol and excess water dried in sterile blotting sheet. Surface sterilized leaves were chopped into small segments and transferred to Saboraud Dextrose Agar (SDA) plates supplemented with streptomycin $(100 \mu \mathrm{g} / \mathrm{ml})$ to suppress bacterial growth. These plates were sealed with parafilm and incubated at $28^{\circ} \mathrm{C}$ for 3-7 days. Plates were monitored every day to check the growth of endophytic fungal colonies from the segments. After the incubation period, the hyphal tips of the developing fungal colonies were transferred to fresh SDA slants and also SDA plates to maintain the pure cultures.

\section{Identification of endophytic fungi}

\section{Morphological and microscopic identification}

In the sporulation stage, fungal mycelium was stained in cotton blue and observed under a microscope. According to their microscopic and morphological appearance, initial identification was done using standard manuals described by $^{22,23}$.

\section{$18 S$ rRNA gene sequencing}

Total genomic DNA of selected G3 isolated endophytic fungi was isolated directly from actively growing mycelium scraped from SDA plates, using EXpure Microbial DNA isolation kit according to manufacturer's protocol (Bogar Bio Bee stores Pvt Ltd.,). DNA amplification was performed by PCR using Taq master mix polymerase and the primer pair ITS 1: 5' AGAGTTTGATCTGGCTCAG 3'; and ITS 4: 5' TACGGTACCTTGTTACGACTT 3' (Millipore) (White et al. 1990) in a thermocycler. PCR was carried out according to the following protocol: initial denaturation 95ㅇ C for $2 \mathrm{~min}$; denaturation 950 C for 30sec; annealing $50 \mathrm{C}$ for $30 \mathrm{~s}$; extension $72 \circ \mathrm{C}$ for $2 \mathrm{~min}$; final extension $72 \circ \mathrm{C}$ for $10 \mathrm{~min}$ and steps 2-4 were repeated 25 cycles. Each sample prepared for PCR consisted of $5 \mu \mathrm{L}$ of isolated DNA in $25 \mu \mathrm{L}$ of PCR reaction solution (1.5 $\mu \mathrm{L}$ of Forward Primer and Reverse Primer), $5 \mu \mathrm{L}$ of deionized water, and $12 \mu \mathrm{L}$ of Taq Master Mix.

Purification of PCR Product was done by using Montage PCR clean up kit (Millipore) protocol. The PCR product was sequenced using the primers. Sequencing reaction were performed using a ABI PRISM ${ }^{\circledR}$ BigDyeTM terminator Cycle Sequencing Kits with AmpliTaq ${ }^{\circledR}$ DNA polymerase (FS enzyme) (Applied Biosystems). The fluorescent- labelled fragments were purified from the unincorporated terminators with an ethanol precipitation protocol. The samples were resuspended in distilled water and subjected to electrophoresis in an $A B I 3730 x$ l sequencer (Applied Biosystems). To identify the isolates, sequences were subjected to the BLAST search with the NCBI database. Multiple sequence alignments of sequences was used by the program MUSCLE $3.7^{24}$. The resulting aligned sequences were cured using th rogram Gblocks $0.91 \mathrm{~b}$. Finally, the program PhyML 3.0 Alrt was used for phylogeny analysis and HKY85 as substitution model. The obtained sequences were then analysed using the BLAST algorithm and closely related phylogenetic sequences obtained from the National Centre of Biological Information (NCBI) database. The phylogenetic tree was constructed using Neighbour Joining method in MEGA $5^{25}$.

\section{Preparation of fungal extract}

The cultivation of fungus was done on $400 \mathrm{ml}$ Saboraud Dextrose Broth (SDB) by placing agar blocks of actively growing pure fungal strains in a $500 \mathrm{ml}$ Erlenmeyer flask. Each flask was incubated at room temperature for 21days with periodical shaking at $150 \mathrm{rpm}$. The cultures were taken out and filtered through sterile muslin cloth to remove the mycelia mats. The culture filtrate was then filtered according to ${ }^{26}$ with some modification by centrifugation at 3,600 rpm for $10 \mathrm{mins}$ and supernatant was extracted thrice with equal volumes of solvent ethyl acetate. The organic phase was collected and the solvent was removed by evaporation under reduced pressure at $45^{\circ} \mathrm{C}$ using a rotary vacuum evaporator. The dry solid residue was re-dissolved in ethyl acetate or dimethyl sulphoxide (DMSO) and subjected to bioassays.

\section{Bioassays}

\section{Anti-bacterial activity}

Test microorganisms

The common foodborne human pathogenic microorganisms were obtained from medical college, 
Yenepoya University, Mangalore, India. One Gram-positive (Enterococcus faecalis) and four Gram-negative (Escherichia coli, Salmonella typhi, and Shigella sonnei) strains were used throughout the study. Tested bacteria were inoculated in nutrient broth and incubated for $24 \mathrm{hrs}$ at $37^{\circ} \mathrm{C}$ in aerobic condition. The suspension was adjusted to 0.5 McFarland turbidity standard correspondingly $\left(\sim 1.5 \times 10^{8} \mathrm{CFU} / \mathrm{ml}\right)$.

\section{Antibacterial activity by agar well diffusion method}

The Agar-well diffusion method was used to screen the antibacterial activity of fungal extracts using nutrient agar (NA) medium according to ${ }^{27}$. A fresh bacterial suspension adjusted to 0.5 McFarland turbidity standard $\sim 1.5 \times 10^{8}$ $\mathrm{CFU} / \mathrm{ml}$ was spread on NA plates with a sterile cotton swab. Using sterile cork borer $6 \mathrm{~mm}$ wells were made in which $100 \mu$ l of crude DMSO extract was loaded on seeded plates. Positive control was maintained by using standard antibiotics, viz Streptomycin at a concentration of $1 \mathrm{mg} / \mathrm{ml}$ according to Kirby-Bauer disk diffusion susceptibility test protocol with minor modification, and Negative control was also maintained using DMSO. The culture plates were then incubated at $370 \mathrm{C}$ for $24 \mathrm{~h}$. The experiment was carried out in three replicates and an inhibition zone was recorded.

\section{Determination of minimum inhibitory concentrations (MICs) and minimal bactericidal concentrations (MBCs).}

The crude extract G3 isolate that showed a potent antimicrobial activity was further assessed for MIC and $\mathrm{MBC}$ assays. The test samples of the crude extracts were dissolved in DMSO. Dilutions were prepared to get final concentrations ranging from 0 to $50 \mathrm{mg} / \mathrm{mL}$. Each well received $10 \mu \mathrm{l}$ suspension of microorganisms and $100 \mu \mathrm{l}$ liquid culture media. Plates were incubated at $370 \mathrm{C}$ for $24 \mathrm{~h}, 15 \mu \mathrm{l}$ of $0.01 \%$ resazurin was added to characterize cell viability then re-incubated for $4 \mathrm{~h}$. The absence of bacterial growth with the lowest concentration was taken as the MIC. Using the results of MIC were determined by sub-culturing which showed no bacterial growth on agar plates after incubated at $37^{\circ} \mathrm{C}$ for $24 \mathrm{~h}$ in an incubator. The complete absence of growth on the agar surface at the lowest sample concentration was defined as the MBC. All experiments were conducted in triplicate. The results were represented as mean $\pm \mathrm{sd}^{28}$.

\section{Anti-diabetic activity}

\section{$\alpha$-Amylase Inhibition Assay}

Alpha-amylase activity was carried out using a modified method described previously by ${ }^{29}$. Briefly, $50 \mu \mathrm{l}, 100 \mu \mathrm{l}$, and $200 \mu$ of different sample concentrations dissolved in DMSO were added to $150 \mu$ l starch solution (containing $1 \%$ starch and $17 \mathrm{mM} \mathrm{NaCl}$ ). The reaction was initiated by adding $10 \mu \mathrm{l} \alpha$-amylase $(1 \mathrm{mg} / \mathrm{ml}$ in $0.1 \mathrm{M}$ sodium phosphate buffer, $\mathrm{pH}$ 7.0) to the mixture and was incubated at room temperature. After $30 \mathrm{~min}$, the reaction was stopped by adding $20 \mu \mathrm{l}$ of $\mathrm{NaOH}$ solution (2M). Subsequently, $20 \mu \mathrm{l}$ of dinitrosalicylic acid was added to the reaction mixture and placed in a water bath for $20 \mathrm{~min}$. The enzymatic hydrolysis of substrate was monitored at $540 \mathrm{~nm}$ using a spectrophotometer. For each concentration, blank tubes were prepared by replacing the enzyme solution with buffer. Acarbose as a positive control was taken and control representing enzyme activity was replacing the plant extracts with DMSO. The experiments were repeated thrice using the same protocol.

The alpha-amylase inhibitory activity was calculated using the formula:

$$
\begin{aligned}
& \% \text { inhibitory activity } \\
& =\frac{\text { Absorbance }(\text { Control })-\text { Absorbance (Extract) }}{\text { Absorbance (Control) }} \times 100
\end{aligned}
$$

The mode of inhibition of endophytic extract on alphaamylase action was determined by increasing substrate (starch) concentration. Kinetic parameters, namely Michaelis-Menten constant affinity $(\mathrm{Km})$ and maximum velocity (Vmax) were derived from appropriate Lineweaver- Burk plots.

\section{Phytochemical Screening}

Preliminary phytochemical screening was performed on the endophytic fungal extracts to detect different phytochemicals such as phenols, flavonoids, alkaloids, terpenoids, saponins, tannins, glycosides, and steroids using standard methods ${ }^{30}$.

\section{Antioxidant assay}

\section{Total phenolic content (TPC)}

Determination of Total Phenolic Content (TPC) of ethyl acetate extract was determined by Folin-Ciocalteu method $^{31}$. One $\mathrm{ml}$ of the extract was added to $2 \mathrm{ml}$ of distilled water and $1 \mathrm{ml}$ of Folin Ciocalteu phenol reagent. The mixture was allowed to stand at room temperature for $5 \mathrm{~min}$ and then $2 \mathrm{ml}$ of sodium carbonate was added to the mixture. The resulting mixture was read at $765 \mathrm{~nm}$ using a UV visible spectrometer against blank. Gallic acid was used to calculate the standard curve (0.01- $0.08 \mathrm{mM} ; \mathrm{Y}=0.026 \mathrm{X}$ $\left.+0.121 ; R^{2}=0.979\right)$ and the results were expressed as $m g$ of gallic acid equivalents (GAEs).

\section{DPPH free radical scavenging assay}

DPPH (2,2-Diphenyl-1-picrylhydrazyl) was performed on selected fungal extracts to measure their ability to decolorize the purple-colored methanol solution of DPPH, as described by ${ }^{32}$. In brief $3 \mathrm{ml}$ of $0.3 \mathrm{mM}$ methanolic solution $(4 \mathrm{mg} / 100 \mathrm{ml})$ of DPPH solution was added to $3 \mathrm{ml}$ of extract and shaken vigorously, the tubes were kept in dark for incubation at room temperature for $30 \mathrm{~min}$. Ascorbic acid (0.5 to $1.5 \mu \mathrm{M}$ ) was used as a positive control. The absorbance was checked against the blank at $516 \mathrm{~nm}$. The scavenging activity was measured based on the extent of bleaching of purple-colored methanol solution of DPPH treated with fungal extract and the percentage (\%) of radical scavenging activity was calculated according to the equation. 
\%DPPH radical scavenging activity $=\frac{\text { Absorbance of blank }- \text { Absorbance of sample }}{\text { Absorbance of blank }} \times 100$

\section{Ferric Reducing Antioxidant Power (FRAP) Assay}

In this assay, $10 \mu \mathrm{l}$ of the sample was mixed with $15 \mu \mathrm{l}$ of $0.1 \mathrm{M}$ sodium phosphate buffer $(\mathrm{pH} 6.6)$ and $15 \mu \mathrm{l}$ of potassium ferricyanide $(1 \% \mathrm{w} / \mathrm{v})$ followed by incubation at $50^{\circ} \mathrm{C}$ for $20 \mathrm{~min}$. After $20 \mathrm{~min}$ incubation, $15 \mu \mathrm{l}$ of trichloroacetic acid (10\%) was added in the reaction mixture and mixed well. Distilled water $(55 \mu \mathrm{l})$ and ferric chloride $(110 \mu \mathrm{l}, 10 \% \mathrm{w} / \mathrm{v})$ were added, and the absorbance was measured at $700 \mathrm{~nm}$. Increased absorbance of the reaction mixture indicates increased reducing capability. L-ascorbic acid was taken as a reference standard. All experiments were carried out in triplicates ${ }^{33}$.

\section{Statistical Analyses}

All the assays were performed in triplicate, and the results were expressed as mean values with standard deviations (SD). The significant differences between means represented by letters were obtained by one-way analysis of variance (ANOVA) followed by Tukey's honestly significant difference (HSD) post hoc test $(P<0.05)$. Correlations were calculated on a honey mean basis, according to Pearson's test.

\section{RESULTS AND DISCUSSION}

In the present investigation, after surface sterilization of leaves from Plectranthus amboinicus different endophytic fungi were isolated on SDA medium respectively. A total of five endophytic fungal isolates were classified into five different taxa namely Aspergillus sp., Fusarium sp., Acremonium sp., Trichoderma sp. and Penicillium $s p$. based on their microscopic and morphological appearance. Similar species were also reported from the same plant by ${ }^{34,35,36}$, where host relevance specific to host was observed such as Aspergillus terreus and Penicillium sp. Further, all the isolates were subjected to antibacterial activity against four foodborne pathogens. The preliminary screening results of antibacterial activity showed that the tested endophytic fungi Aspergillus sp., Fusarium sp., Acremonium sp., Trichoderma sp., and Penicillium sp. exhibit inhibition to all the test pathogens (Table. 1) and revealed significant differences among the fungal isolates $(P<0.05)$.

Table 1: Preliminary antibacterial activity screening of fungal endophytes

\begin{tabular}{|c|c|c|c|c|}
\hline \multirow{2}{*}{ Fungal Isolates } & \multicolumn{4}{|c|}{ Zone of inhibition* } \\
\hline Aspergillus sp. & Escherichia coli & Salmonella typhi & Shigella sonnei & Enterococcus faecalis \\
\hline Fusarium sp. & $8.0 \pm 0.0 \mathrm{~d}$ & $22.0 \pm 0.2 \mathrm{~b}$ & $11.0 \pm 0.1 \mathrm{~b}$ & $10.0 \pm 0.0 \mathrm{c}$ \\
\hline Acremonium sp. & $9.0 \pm 0.3 \mathrm{c}$ & $12.0 \pm 0.5 \mathrm{c}$ & $10.0 \pm 0.0 \mathrm{c}$ & $13.0 \pm 0.2 \mathrm{~b}$ \\
\hline Trichoderma sp. & $8.0 \pm 0.0$ & $8.0 \pm 0.0$ & $9.0 \pm 0.0$ & $9.0 \pm 0.0$ \\
\hline Penicillium sp. & $10.0 \pm 0.1 \mathrm{~b}$ & $8.0 \pm 0.0 \mathrm{e}$ & $10.0 \pm 0.4 \mathrm{c}$ & $10.0 \pm 0.0 \mathrm{c}$ \\
\hline Streptomycin $(1 \mathrm{mg} / \mathrm{ml})$ & $8.0 \pm 0.0 \mathrm{~d}$ & $10.0 \pm 0.0 \mathrm{~d}$ & $11.0 \pm 0.2 \mathrm{~b}$ & $8.0 \pm 0.0 \mathrm{~d}$ \\
\hline
\end{tabular}

The isolates which showed antibacterial activity in preliminary screening were further subjected for fermentation assay and the crude extracts were obtained through ethyl acetate extraction. The obtained crude extract was subjected to secondary screening and showed a better zone of inhibition against tested pathogens (Table. 2 ) compared to the preliminary assay. A similar study was found $b^{37}$ on Basella rubra $\mathrm{L}$. This could be due to the antimicrobial potency of the extract to the high concentration of unidentified active principle in the extract. The crude extracts of endophytic fungi yielded more potent compounds once they had undergone some purification $^{38}$.

Table 2: Secondary antibacterial screening of fungal endophytes

\begin{tabular}{|c|c|c|c|c|}
\hline \multirow{2}{*}{ Fungal Isolates } & \multicolumn{4}{|c|}{ Zone of inhibition* } \\
\hline & Escherichia coli & Salmonella typhi & Shigella sonnei & Enterococcus faecalis \\
\hline Aspergillus sp. & $10.0 \pm 0.0 \mathrm{c}$ & $26.0 \pm 0.2 \mathrm{~b}$ & $13.0 \pm 0.1 \mathrm{c}$ & $12.0 \pm 0.0 \mathrm{c}$ \\
\hline Fusarium sp. & $10.0 \pm 0.6 \mathrm{c}$ & $14.0 \pm 0.2 \mathrm{c}$ & $12.0 \pm 0.0 \mathrm{~d}$ & $15.0 \pm 0.4 \mathrm{~b}$ \\
\hline Acremonium sp. & $9.0 \pm 0.0 \mathrm{~d}$ & $9.0 \pm 0.0 \mathrm{e}$ & $10.0 \pm 0.0 \mathrm{e}$ & $11.0 \pm 0.0 \mathrm{e}$ \\
\hline Trichoderma sp. & $11.0 \pm 0.1 \mathrm{~b}$ & $12.0 \pm 0.0 \mathrm{~d}$ & $13.0 \pm 0.1 \mathrm{c}$ & $12.0 \pm 0.0 \mathrm{c}$ \\
\hline Penicillium sp. & $11.0 \pm 0.0 \mathrm{~b}$ & $12.0 \pm 0.0 \mathrm{~d}$ & $14.0 \pm 0.7 \mathrm{~b}$ & $11.0 \pm 0.0 \mathrm{~d}$ \\
\hline Streptomycin $(1 \mathrm{mg} / \mathrm{ml})$ & $25.0 \pm 0.3 \mathrm{a}$ & $30.0 \pm 0.4 \mathrm{a}$ & $22.0 \pm 0.5 \mathrm{a}$ & $28.0 \pm 0.3 \mathrm{a}$ \\
\hline
\end{tabular}

*Values are means of three independent replicates. \pm Standard deviation; Means in the same column with different letters are significantly $(P<0.05)$ different. 
The crude extract Aspergillus sp. was selected to determine the MIC and MBC by microdilution technique against E. coli, S. typhi, Sh. sonnei and E. faecalis (Table. 3) based on the good zone of inhibition against all tested pathogens in secondary antibacterial screening. The result revealed $10 \mathrm{mg} / \mathrm{ml}$ low concentration of $\mathrm{MIC}$ and $40 \mathrm{mg} / \mathrm{ml}$ high concentration of $\mathrm{MBC}$. The observed variations are due to the synergistic effect of the different congener components within one sample ${ }^{39}$. Upon serially diluting the content of the well where no resazurin color change was observed.

Table 3: MIC and MBC (mg/ml) values of crude Aspergillus extract against foodborne pathogens.

\begin{tabular}{|l|c|c|c|c|c|c|c|c|}
\hline \multirow{2}{*}{ Fungal Isolates } & \multicolumn{2}{|c|}{ E. coli } & \multicolumn{2}{c|}{ S. typhi } & \multicolumn{2}{c|}{ Sh. sonnei } & \multicolumn{2}{c|}{ E. faecalis } \\
\cline { 2 - 10 } & MIC & MBC & MIC & MBC & MIC & MBC & MIC & MBC \\
\hline Aspergillus sp. & 10 & 20 & 15 & 10 & 10 & 20 & 20 & 40 \\
\hline
\end{tabular}

The presence of phytochemicals in endophytes is an indicator that they can be a potential source of precursors in the development of synthetic drugs ${ }^{40}$. Phytochemical analysis of ethyl acetate solvent extract revealed the presence of phenol, flavonoids, alkaloids, terpenoids, steroids, saponin, tannins, and glycosides. The crude fungal extracts gave a wide variety of presence and absence of phytochemicals given in Table. 4.

Table 4: Phytochemical screening of Aspergillus terreus ethyl acetate extract.

\begin{tabular}{|c|c|c|c|c|c|c|c|c|}
\hline Fungal Isolates & Phenol & Flavonoids & Alkaloids & Terpenoids & Steroids & Saponin & Tannins & Glycosides \\
\hline Aspergillus sp. & + & + & + & - & + & + & + & - \\
\hline Fusarium sp. & + & - & + & + & - & - & + & + \\
\hline Acremonium sp. & + & - & + & - & + & - & - & + \\
\hline Trichoderma sp. & + & + & - & - & - & + & - & - \\
\hline Penicillium sp. & + & - & + & - & - & + & + & - \\
\hline
\end{tabular}

The endophytes which revealed the presence of different phytochemicals are known to possess strong antimicrobial and antioxidant activity. The antioxidant capacities of the endophytic fungal cultures were correlated with their total phenolic contents, suggested that phenolic were also the major antioxidant constituents of the endophytes ${ }^{41}$. The ethyl acetate extract of Aspergillus sp. revealed good phenolic content as well as radical scavenging activity and suggested phenolic content represent the major group of compounds that act as primary free radical scavengers. Total phenolic content was found to be $5.08 \pm 0.6$ expressed in gallic acid equivalents (GAE) $\mathrm{mg} / \mathrm{ml}$ and the antioxidant potential was evaluated by DPPH and FRAP assay. The effect of antioxidants on DPPH is thought to be to their hydrogen donating ability ${ }^{42,43}$ where freshly prepared DPPH solution exhibits a deep purple color which disappears when an antioxidant is present in the medium indicating that the metabolites of Aspergillus sp. could be potential agents in scavenging free radicals and treating diseases related to free radical reactions. The FRAP assay measures antioxidants in a sample at $593 \mathrm{~nm}$ compared to other assays measuring inhibition of free radicals exhibit $68.13 \pm 0.26$ (AAE mg/ml) indicating their electrondonating potential. Where, the value of FRAP is directly proportional to its antioxidant capacity, as in this assay, antioxidants act as reducing agents by donating electrons to ferric ion. The results obtained in the DPPH and FRAP assay indicated high activity (Figure. 1).

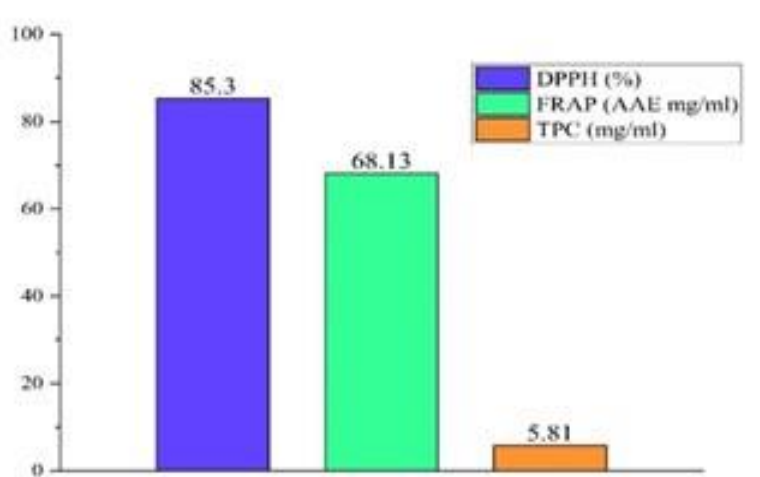

Figure 1: Antioxidant activity of Aspergillus terreus ethyl acetate extract

A significant positive correlation between total phenolic content and antioxidant activity was observed in our study (Table. 5). A positive correlation was found between FRAP and TPC, DPPH and FRAP was $\mathrm{R}=0.942$ and $\mathrm{R}=0.975$ respectively. The correlation between TPC and DPPH free radical scavenging activity was also studied and it was observed to be highly positively correlated with $R=0.987$. The antioxidant activity of phenolics can be interpreted due to the increase with which they can act as reducing agents, hydrogen donors or singlet oxygen quenchers ${ }^{44}$. These results indicate that extract having more phenolic content tends to serve a strong antioxidant activity. Earlier studies on the screening of endophytic extracts for antioxidants from medicinal plants have revealed the chemical diversity of phenolic compounds from endophytes ${ }^{45}$. 
Table 5: Correlation matrix (Pearson's correlation coefficients)

\begin{tabular}{|c|c|c|c|}
\hline Variable & TPC & FRAP & DPPH \\
\hline DPPH & $0.987^{* *}$ & $0.975^{* *}$ & - \\
\hline FRAP & $0.942^{* *}$ & - & \\
\hline TPC & - & & \\
\hline \multicolumn{4}{|c|}{ ** Correlation is significant at the 0.01 level } \\
\hline
\end{tabular}

The study on synergistic antidiabetic activity was performed to detect the inhibition by alpha-amylase assay. Alpha-amylase is an enzyme that hydrolyses carbohydrates into glucose, and easily absorbable ${ }^{46}$. The crude extract Aspergillus sp. isolates in different concentrations of 50,100 , and $200 \mu \mathrm{g} / \mathrm{ml}$ gave a potent antidiabetic activity. The antidiabetic activity in the concentrations $50,100,200 \mu \mathrm{g} / \mathrm{ml}$ was $68.12 \%, 34.18 \%$ and $75.31 \%$ respectively. The highest antidiabetic activity was observed in the concentration of $200 \mu \mathrm{g} / \mathrm{ml}$ (Figure 2). This study reveals that endophytic fungi inhibit the activity of alpha-amylase could be a potential source of developing remarkable antidiabetic drugs. These drugs could control diabetes by inhibiting a major enzyme alpha-amylase that hydrolyzes carbohydrates into sugar ${ }^{47}$.

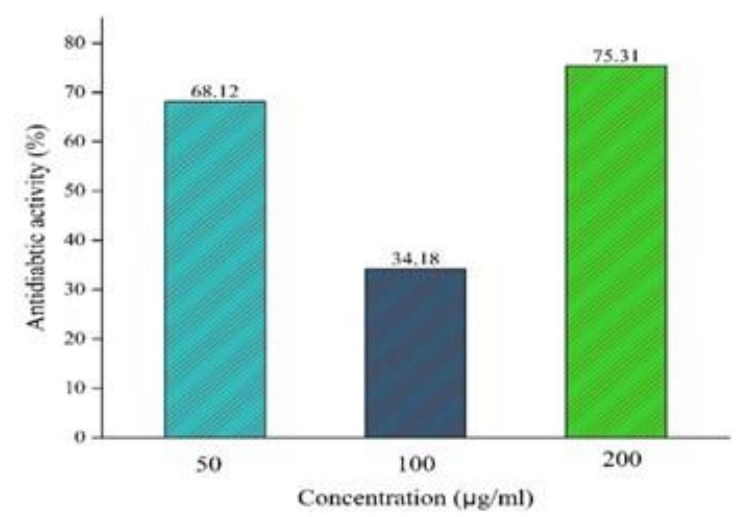

Figure 2: Showing amylase activity in different concentration of Aspergillus terreus ethyl acetate extract

Finally, Aspergillus sp. (Figure. 3) were considered for molecular characterization. The rDNA-ITS region was amplified, sequenced, and submitted to the NCBI GenBank with accession number MW391576. A BLAST search of ITS gene sequences reveals the endophytic fungal isolates to be the closest homolog of Aspergillus terreus (Figure. 4). To the best of our knowledge, this study considers a first report conducted on anti-diabetic and antioxidant activity of ethyl acetate extract of endophytic fungi isolated from Plectranthus amboinicus revealed both hosts, as well as its endophyte, are good sources of phytochemicals, antioxidants, antibacterial and antidiabetic activity. Further, elucidating the profile would reveal the presence of similar compounds both in host and endophyte.
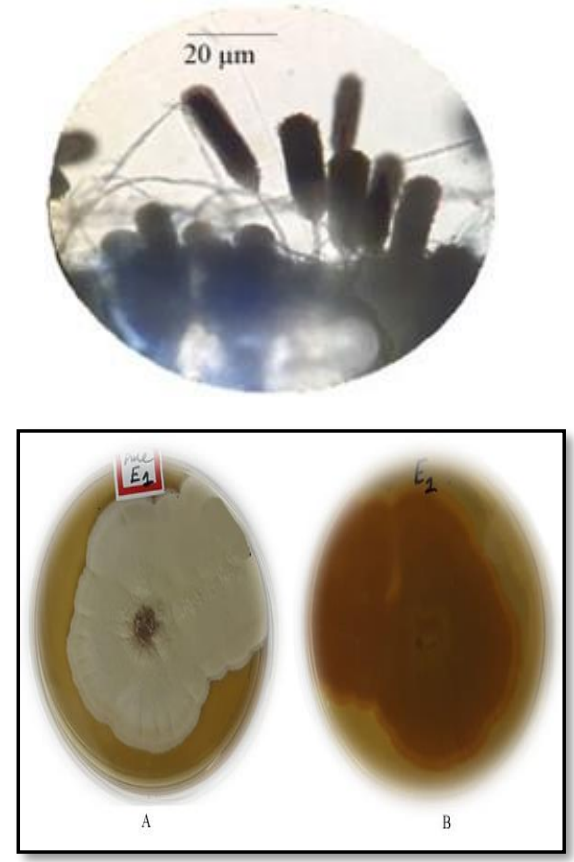

Figure 3: Growth pattern A-Front view; B-Back view and microscopic view of endophytic fungi Aspergillus terreus.

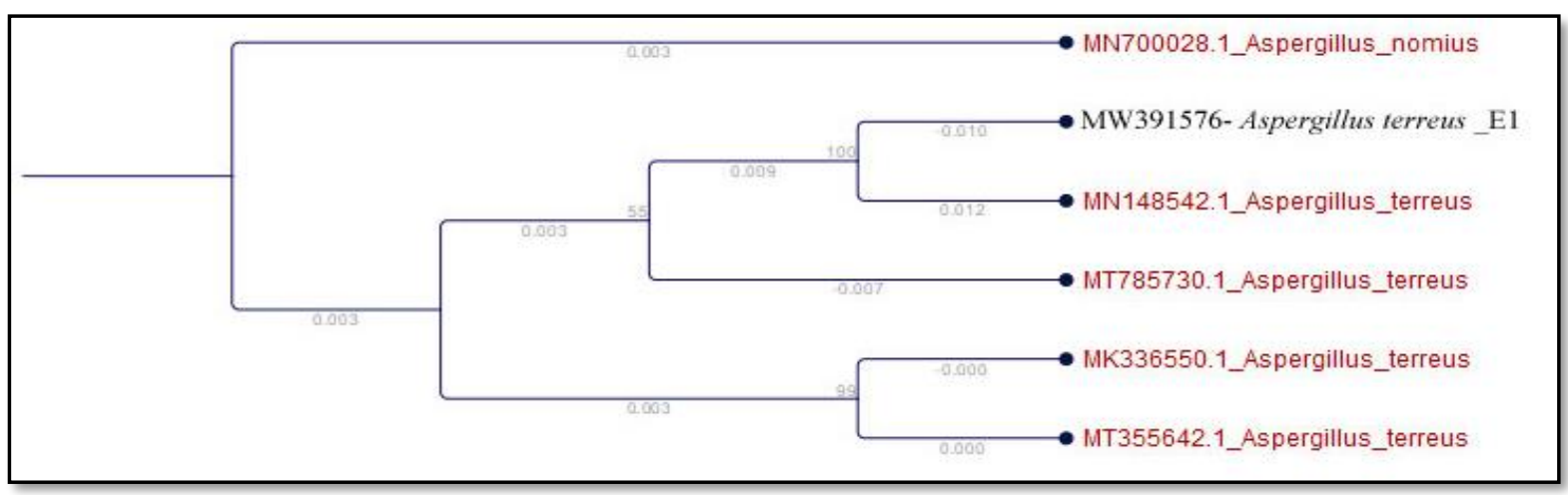

Figure 4: Evolutionary positions of the endophytic fungal isolate E1 with other related fungal species based on internal transcribed spacer sequence similarity. 


\section{CONCLUSION}

The study concludes that Plectranthus amboinicus harbor several endophytic fungi that showed their promising biological activity. The Aspergillus terreus isolate exhibited a promising antibacterial activity with a quite low MIC and high $\mathrm{MBC}$ value by exposing the bactericidal nature of its extract. The extract of Aspergillus terreus also revealed good antidiabetic activity. Therefore, the antidiabetic compounds can be isolated for a potential treatment for DM. The study suggests Aspergillus terreus has a multi biological activity and could be a promising therapeutic agent. These findings will facilitate further studies to gain a better understanding and production of bioactive metabolites.

Acknowledgment: The authors are thankful to the Department of Microbiology, Mangalore University for providing laboratory facilities. We are also thankful to the Yaazh Xenomics lab. Coimbatore- TN for DNA sequencing.

\section{REFERENCES}

1. Maikhuri RK, Rao KS, Saxena KG. Bioprospecting of wild edibles for rural development in central Himalaya. Mountain Research and Development. 2004; 24(2): 110-113.

https://doi.org/10.1659/02764741(2004)024[0110:BOWEFR]2.0.CO;2.

2. Lindeberg S, Cordain L, Eaton SB. Biological and clinical potential of a paleolitic diet. Journal of Nutritional and Environmental Medicine. 2003; 13(3): 149-160. DOI: 10.1080/13590840310001619397.

3. Wise R. The worldwide threat of antimicrobial resistance. Curr Sci. 2008; 95(2): 181-187. https://www.jstor.org/stable/24103044.

4. Guanatilaka AAL. Natural products from plant-associated microorganisms: distribution, structural diversity, bioactivity, and implications of their occurrence. J Nat Prod. 2006; 69: 509-526. https://doi.org/10.1021/np058128n.

5. Schulz B, Boyle C. The endophytic continuum. Mycol Res. 2005; 109(6): 661-686. doi:10.1017/S095375620500273X.

6. Sushma KS, Jayashankar $M$, Mohammed AS, Vinu AK. Antibacterial activity of endophytic fungi from some medicinal plants of Biligirirangana hill, India. Journal of Applied and Natural Science. 2018; 10(4): 1286-1290. DOI https://doi.org/10.31018/jans.v10i4.1923.

7. Maxwell $T$, Blair R, Wang $Y$, Kettring A, Moore S, Rex M, Harper J. A solvent free approach for converting cellulose waste into volatile organic compounds with endophytic Fungi. J. Fungi. 2018;4:102-113. doi:10.3390/jof4030102.

8. Pavithra N, Sathish L, Ananda K. Antimicrobial and enzyme activity of endophytic fungi isolated from tulsi. J Pharm Biomed Sci. 2012; 16(12): 1-6.

9. Tan RX, Zou WX. Endophytes: A rich source of functional metabolites. Nat Prod Rep. 2001; 18(4): 448-59. https://doi.org/10.1039/B1009180.

10. Kaul S, Gupta S, Ahmed M, Dhar MK. Endophytic fungi from medicinal plants: a treasure hunt for bioactive metabolites.
Phytochem Rev. 2012; 11: 487-505. DOI 10.1007/s11101012-9260-6.

11. Verma VC, Gond SK, Kumar A, Kharwar RN, Boulanger LA, Strobel GA. Endophytic fungal flora from roots and fruits of an Indian neem plant Azadirachta indica A. Juss and impact of culture media on their isolation. Ind.J.of Microbiol. 2011; 51: 469-476. doi: 10.1007/s12088-011-0121-6.

12. Kusari S, Pandey SP, Spiteller M. Untapped mutualistic paradigms linking host plant and endophytic fungal production of similar bioactive secondary metabolites. Phytochemistry. 2013; 91: 1-7. http://dx.doi.org/10.1016/j.phytochem.2012.07.021.

13. Ragasa CY, Pendon Z, Sangalang V, Rideout JA. Antimicrobial Flavones from Coleus amboinicus. Phil J Sci. 1999; 128(4): 347-51. DOI:10.1055/s-0028-1097537.

14. Rout SD, Panda SK. Ethnomedicinal plant resources of Mayurbhanj district, Orissa. Indian J Tradit Know. 2010; 9(1): 68-72. http://hdl.handle.net/123456789/7157.

15. Khare RS, Banerjee S and Kundu K. Coleus aromaticus Benth - A Nutritive medicinal plant of potential therapeutic value. Int J Pharm Bio Sci. 2011; 2(3): 488-500.

16. Svara F, Rank RJ. The evolution of plasmid-carried antibiotic resistance. BMC Evol. Biol. 2011; 11: 130. http://www.biomedcentral.com/1471-2148/11/130.

17. Arumugam G, Swamy MK, Sinniah UR. Plectranthus amboinicus (L.) Spreng: Botanical, phytochemical, pharmacological and nutritional significance. Molecules 2016; 21(4): 369. DOI: 10.3390/molecules21040369.

18. Arnold C. The new danger of synthetic drugs. Lancet. 2013; 382: 15-16. DOI: 10.1016/s0140-6736(13)61512-3.

19. Ushasri R, Anusha R. In vitro anti-diabetic activity of ethanolic and acetone extracts of endophytic fungi Syncephalastrum racemosum isolated from the seaweed Gracilariacorticata by alpha-amylase inhibition assay method. Int J Curr Microbiol App Sci. 2015; 4(1): 254-259.

20. Jayanthia G, Kamalraja S, Karthikeyan K, Muthumarya J. Antimicrobial and antioxidant activity of the endophytic fungus Phomopsis sp.GJJM07 isolated from Mesuaferrea. Int J Curr Sci. 2011; 1: 85-90.

21. Vinu AK, Jayashankar M. Seasonality of endophytic fungi: reasoning of medicinal use IJCMS. 2017; 3(8): 794-797.

22. Barnett HL, Hunter BB. Illustrated Genera of Imperfect Fungi. 3rd Edition, Burgess Publishing Co., Minneapolis.; 1972. p. 241.

23. Seifert K, Morgan-Jones G, Gams W and Kendrick B. The Genera of Hyphomycetes. CBS-KNAW Fungal Biodiversity Centre, Utrecht, Netherlands. 2011; 27: 119-129.

24. Edgar RC. MUSCLE: multiple sequence alignment with high accuracy and high throughput. Nucleic Acids Res. 2004; 32(5): 1792-1797. https://doi.org/10.1093/nar/gkh340.

25. Tamura K, Peterson D, Peterson N, Stecher G, Nei M, Kumar S. MEGA5: molecular evolutionary genetics analysis using maximum likelihood, evolutionary distance, and maximum parsimony methods. Mol. Biol. Evol. 2011; 28(10): 27322739. doi: $10.1093 / \mathrm{molbev} / \mathrm{msr} 121$. 
26. Raju DC, Victoria T. Isolation, characterization and antibacterial activity of endophytic fungi from Calophyllum inophyllum L. Der Pharma Chemica. 2015; 7(7): 250-254.

27. Devaraju R, Satish S. "Endophytic mycoflora of Mirabilis jalapa L. and studies on antimicrobial activity of its endophytic Fusarium sp.", Asian J. of Experimental Biological Sciences. 2011; 2: 75-79.

28. Chen H, Tian T, Miao H, Zhao YY. Traditional uses, fermentation, phytochemistry and pharmacology of Phellinus linteus: A review. Fitoterapia. 2016; 113: 6-26. doi: 10.1016/j.fitote.2016.06.009.

29. Picot $\mathrm{CMN}$, Subratty $\mathrm{AH}$, Mahomoodally MF. Inhibitory Potential of Five Traditionally Used Native Antidiabetic Medicinal Plants on $\alpha$-Amylase, $\alpha$-Glucosidase, Glucose Entrapment, and Amylolysis Kinetics In Vitro. Hindawi Publishing Corporation Advances in Pharmacological Sciences. 2014; 7. https://doi.org/10.1155/2014/739834.

30. Ladoh-Yemeda CF, Nyegue MA, Ngene JP, Benelesse GE, Lenta $B$, Wansi JD, Mpondo Mpondo E and Dibong SD. Identification and phytochemical screening of endophytic fungi from stems of Phragmantheracapitata (Sprengel) S. Balle (Loranthaceae). J Appl Biosci. 2015; 90: 8355-60. DOI: 10.4314/jab.v90i1.7.

31. Chang HY, Ho YL, Sheu MJ, Yaw-Huei LI, Tseng MC, Wu SH. Antioxidant and free radical scavenging activities of Phellinus merrillii extracts. Bot Stud. 2007; 48(4): 407-417.

32. Asker MMS, Mohamed SF, Mahmoud MG, El Sayed OH. Antioxidant and antitumor activity of a new sesquiterpene isolated from endophytic fungus Aspergillus glaucus. Int J PharmTech Res. 2013; 5(2): 391-397.

33. Tuba AK, Gulcin I. Antioxidant and radical scavenging properties of curcumin. Chem Biol Interact. 2008; 174(1): 27-37. doi: 10.1016/j.cbi.2008.05.003.

34. Kartikeya T, Manjuu G. Novel endophytic Penicillium chrysogenum strains isolated from Plectranthus amboinicus L. of West Malaysia. Res. J. Microbiol. 2020; 15: 15-21. DOI: $10.3923 / \mathrm{jm} .2020 .15 .21$.

35. Campos RPC, Jacob JKS, Ramos HC, Temanel FB. Mycopharmacological Properties of Endophytic Fungi Isolated from Cuban Oregano (Plectranthrus amboinicus L.) Leaves. Asian J Biol Life Sci. 2019; 8(3): 103-110. DOI: 10.5530/ajbls.2019.8.17.

36. Duraisamy $E$, Velu $M$, Palaniyappan , Palanivel V, Balasubramanian B, Arumugam VR, Muthugounder SS. Selection and characterization of extracellular enzyme production by an endophytic fungi Aspergillus sojae and its bio-efficacy analysis against cotton leaf worm, Spodoptera litura, Current Plant Biology. 2020; 23: 2214-6628. https://doi.org/10.1016/j.cpb.2020.100153.
37. Hema $\mathrm{P}$, Murali M, Thriveni MC, Prathibha M, Jayaramu SC, Amruthesh $\mathrm{KN}$. Phytochemical analysis and antibacterial activity of endophytic fungi isolated from Basella rubra L.-A medicinal plant. J Pure Appl. Microbio. 2015; 9(4): 29712978.

38. Fabry W, Okemo PO, Ansorg R. Antibacterial activity of East African medicinal plants. J Ethno pharmacol. 1998; 60: 7984. https://doi.org/10.1016/S0378-8741(97)00128-1.

39. Das P, Yang XP, Ma LZ. Analysis of biosurfactants from industrially viable Pseudomonas strain isolated from crude oil suggests how rhamnolipids congeners affect emulsification property and antimicrobial activity. Front Microbiol. 2014; 5: 696. DOI: 10.3389/fmicb.2014.00696.

40. Jack IR, Okorosaye OK. Phytochemical analysis and antimicrobial activity of the extract of leaves of Fleabane (Conyza sumatrensis). J. Appl. Sci. Environ. Manage., 2008, 12(4): 63-65. DOI:10.4314/jasem.v11i4.55196.

41. Wu-Yang H, Yi-Zhong C, Xing J, Harold C, Sun M. A potential antioxidant resource: Endophytic fungi from medicinal plants. Economic Botany. 2007; 61(1): 14-30 DOI:10.1663/00130001(2007)61\%5B14:APAREF\%5D2.0.CO;2.

42. Biswas M, Haldar PK, Ghosh AK. Antioxidant and free-radical scavenging effects of fruits of Dregea volubilis. J. Nat. Sci. Biol. Med. 2010; 1(1): 29-34. DOI: 10.4103/09769668.71670 .

43. Meir S, Kanner J, Akiri B, Philosoph-Hadas S. Determination and involvement of aqueous reducing compounds in oxidative defense system of various senescing leaves. J. Agr. Food Chem. 1995; 43(7): 1813-9. https://doi.org/10.1021/jf00055a012.

44. Katerere, David \& Graziani, Giulia \& Thembo, Kaizer \& Nyazema, Norman \& Ritieni, Alberto. Antioxidant activity of some African medicinal and dietary leafy African vegetables. African journal of biotechnology. 2012; 11(17): 4103-4108. 10.5897/AJB11.3674. DOI: 10.5897/AJB11.3674.

45. Archana N, Jyoti P, Joshi SR. Bioactivity assessment of endophytic fungi associated with Centella asiatica and Murraya koengii. Journal of Applied Biology \& Biotechnology. 2014; 2(5): 006-011. DOI: 10.7324JABB.2014.2502.

46. Kellogg J, Grace MH, Lila MA. Phlorotannins from Alaskan seaweed inhibit carbolytic enzyme activity. Marine drugs. 2014; 12 5277-5294. https://doi.org/10.3390/md12105277.

47. Surya S, Salam AD, Tomy DV, Carla B, Kumar RA, Sunil C. Diabetes mellitus and medicinal plasnts-a review. Asian Pac J Trop Dis. 2014; 4(5): 337-347. https://doi.org/10.1016/S2222-1808(14)60585-5.

Source of Support: The author(s) received no financial support for the research, authorship, and/or publication of this article.

Conflict of Interest: The author(s) declared no potential conflicts of interest with respect to the research, authorship, and/or publication of this article.

For any question relates to this article, please reach us at: editor@globalresearchonline.net New manuscripts for publication can be submitted at: submit@globalresearchonline.net and submit ijpsrr@rediffmail.com 